\title{
Metabolismo de nitrogênio em dois sistemas de cultivo de café sob veranico da estação úmida
}

\author{
Carmem Lacerda Lemos ${ }^{1}$, Sylvana Naomi Matsumoto², Anselmo Eloy Silveira Viana ${ }^{2}$ \\ Renato Alves Coelho ${ }^{3}$, Fábio Ricardo Coutinho Fontes César ${ }^{4}$
}

\section{RESUMO}

Com o objetivo de avaliar o efeito do veranico ocorrido na estação úmida sobre o metabolismo de nitrogênio em cafeeiros em sistema a pleno sol e associados com abacateiro (Persea americana Mill.) e ingazeiro (Inga edulis Mart.), foi realizado este experimento.

O estudo foi conduzido em propriedade situada no município de Barra do Choça, BA, composto por plantas de café (Coffea arabica L.), variedade Catuaí, sendo caracterizados dois campos experimentais (sistema sombreado x sistema a pleno sol). As avaliações foram realizadas em janeiro (período de veranico) e março (final da estação úmida), em cinco repetições por campo experimental. Os dados foram submetidos ao teste t por meio do programa SAEG, versão 9.1. Maior teor de $\mathrm{NO}_{3}{ }^{-}$foi verificado no sistema a pleno sol, tanto no período de veranico como no final da estação úmida. Em março foi observado maior acúmulo de N-orgânico no terço superior do cafeeiro a pleno sol e no terço médio do cafeeiro sombreado. Maiores teores de nitrogênio total e tendência de maior atividade enzimática da redutase do nitrato foram verificados nos sistemas arborizados, quando avaliados dentro do mesmo terço do cafeeiro nas duas estações.

Palavras chave: Arborização, crescimento, redutase do nitrato, Coffea arabica L.

\section{ABSTRACT}

\section{Nitrogen metabolism in two coffee cultivation systems during drought period of the rainy season}

The objective of this work was to evaluate the influence of a short drought period in the middle of the rainy season on nitrogen assimilation of coffee plants shaded by avocado (Persea americana Mill.) and Inga edulis Mart. in comparison with unshaded plants, in January (drought period of rainy season) and March (end of rainy season), with 5 replications per experimental field. The highest nitrate- $\mathrm{N}$ foliar content was observed in the full sun system, in all evaluations. In March, there was higher organic $\mathrm{N}$ accumulation in the upper third of the canopy of full sun plants and in the middle part of the shaded coffee. Higher values of nitrate- $\mathrm{N}$ and a tendency to a higher nitrate reductase activity were found in the shaded coffee, when evaluations were carried out in the same part of the coffee canopy..

Key words: Tree planting, growth, nitrate reductase, Coffea arabica L.

\footnotetext{
Recebido para publicação em agosto de 2008 e aprovado em setembro de 2009

${ }^{1}$ Engenheira-Agrônoma. Mestre. Universidade Estadual do Sudoeste da Bahia/UESB. Cx. P. 95, 45000-000, Vitória da Conquista, Bahia, Brasil. lemoscarmem@yahoo.com.br. Engenheiros-Agrônomos, Doutores. Universidade Estadual do Sudoeste da Bahia, Departamento de Fitotecnia e Zootecnia, Cx. P. 95. 45000-000, Vitória da Conquista, Bahia, Brasil.snaomi@uesb.br; ae-viana@uol.com.br.

${ }^{3}$ Licenciado em Ciências Agrícolas. Mestre. Universidade Estadual do Sudoeste da Bahia, Cx. P. 95. 45000-000, Vitória da Conquista, Bahia, Brasil. Bolsista Fapesb.

${ }^{4}$ Engenheiro-Agrônomo, Universidade Estadual do Sudoeste da Bahia, Cx. P. 95. 45000-000, Vitória da Conquista, Bahia, Brasil.
} 


\section{INTRODUÇÃO}

A Bahia é um dos estados do Brasil onde a cafeicultura se desenvolveu expressivamente nos últimos anos. $\mathrm{O}$ cultivo de café na Bahia localiza-se em três regiões edafoclimáticas distintas: Sudoeste, Extremo Sul e Oeste. A região Sudoeste é caracterizada pela ocorrência de intenso veranico em meados da estação úmida (novembro a março), que restringe a produtividade de diversas culturas agrícolas praticadas no município de Barra do Choça (Sousa et al., 2007). Uma das alternativas para minimizar esse problema é a associação de árvores aos cafezais. A arborização tem o objetivo principal de amenizar as condições ambientais desfavoráveis para os cafeeiros, reduzindo a luminosidade e temperatura e protegendo-os contra ventos. Matsumoto et al. (2006) verificaram que a umidade dos solos sob a copa de grevíleas é superior àquela de áreas não-sombreadas, resultando em menor nível de estresse nos cafeeiros, verificado pelo menor acúmulo de prolina nas folhas.

O nitrogênio é um dos nutrientes mais afetados pela disponibilidade hídrica, principalmente na fase de frutificação, quando é intensamente transportado das folhas para os frutos, seja em condição de suprimento adequado ou deficiente (Lima Filho \& Malavolta, 2003).

Apesar da alta habilidade de aclimatação nos diferentes níveis de irradiância, as plantas de café parecem manter características genéticas das espécies adaptadas à sombra em relação à assimilação do nitrato. A atividade da redutase do nitrato ( $\mathrm{RN}$ ) em folhas de café é geralmente maior em plantas sombreadas parcialmente (50\% de luz) do que naquelas a pleno sol (Andrade Netto, 2005). As árvores podem elevar a quantidade e a disponibilidade de nutrientes dentro da zona de atuação do sistema radicular das culturas associadas, por meio do acréscimo de nitrogênio $(\mathrm{N})$, que é resultante da fixação biológica de $\mathrm{N}_{2}$, da recuperação de nutrientes abaixo do sistema radicular das culturas agrícolas, da redução das perdas de nutrientes por processos como lixiviação e erosão e do aumento da disponibilidade de nutrientes pela sua maior liberação na matéria orgânica do solo (Ribaski et al., 2002).

O presente trabalho teve como objetivo avaliar o efeito do veranico ocorrente na estação úmida sobre o metabolismo de nitrogênio em cafeeiros em sistema a pleno sol e associados com abacateiro (Persea americana) e ingazeiro (Inga edulis).

\section{MATERIAL E MÉTODOS}

O estudo foi conduzido no período de janeiro a março de 2007, em propriedade particular situada no município de Barra do Choça, Bahia. O município está localizado na latitude $14^{\circ} 51^{\prime}$ '58' 'S e longitude $40^{\circ} 34^{\prime} 44^{\prime \prime}$ W, a $875 \mathrm{~m}$ acima do nível do mar, na região Sudoeste da Bahia, ca- racterizada por pluviometria média anual de $900 \mathrm{~mm}$, com concentração das chuvas nos meses de novembro a março. Em janeiro e fevereiro apresenta período de estiagem e deficiência hídrica, veranico da estação úmida, que adquire grande importância econômica, devido ao seu impacto na produtividade das culturas. A temperatura média anual oscila entre 19,6 e $20,2^{\circ} \mathrm{C}$.

O experimento foi composto por dois campos de observação: cafeeiros (Coffea arabica L. cv. Catuaí Vermelho (IAC 144)), cultivados no espaçamento 3 x $1 \mathrm{~m}$ em sistema a pleno sol e associados com abacateiro (Persea americana), e ingazeiro (Inga edulis), plantados em espaçamento irregular. Foram coletadas amostras do $3^{\circ} \mathrm{e}$ do $4^{\circ}$ pares de folhas de ramos situados nos terços superior e médio do cafeeiro. Em cada terço foram coletadas folhas nos pontos cardeais (N, S, L, O) de cada planta. As avaliações foram realizadas em cinco repetições por campo experimental.

O material vegetal coletado foi seco em estufa de ventilação forçada a $65^{\circ} \mathrm{C}$, por 48 horas. Posteriormente, as folhas secas foram trituradas em moinho tipo Willey e acondicionadas em vidros para realização das análises.

Para determinação do nitrogênio total pelo processo semimicro Kjeldahl, o material vegetal, seco e moído, foi submetido à digestão sulfúrica (Silva \& Queiroz, 2002), bem como à extração com água, em banho-maria, para análise do nitrato (Cataldo et al., 1975). A determinação de N-orgânico foi obtida pela diferença entre os teores de nitrogênio total e nitrato. A determinação da atividade da RN foi realizada empregando-se o ensaio in vivo, de acordo com Queiroz et al. (1991). As coletas foram realizadas com intervalo de seis horas entre as avaliações, que foram efetuadas às 6,12 e 18h. Esse procedimento foi adotado para permitir a comparação da ação enzimática nas diferentes condições de luminosidade do experimento (pleno sol e sombreado) ao longo do período luminoso. A leitura foi realizada em espectrofotômetro a $540 \mathrm{~nm}$, sendo a atividade da enzima determinada pela quantidade de nitrito produzida, comparando os valores obtidos com uma curva-padrão para esse íon, previamente estabelecida. Os resultados obtidos foram expressos em $\mu$ mol $\mathrm{NO}_{2}{ }^{-} \mathrm{h}^{-1} \mathrm{~g}^{-1} \mathrm{MF}$.

A comparação entre as médias das características observadas foi realizada por meio do teste t, utilizando o Sistema para Análises Estatísticas e Genéticas (SAEG, 2000) versão 9.1, adotando-se para análise dos dados o nível de significância de $10 \%$.

\section{RESULTADOS E DISCUSSÃO}

Em janeiro (Figura 1), para todos os horários de avaiação não houve diferença no teor de nitrogênio total (NT) entre os terços superior e médio dos cafeeiros, tanto no sistema a pleno sol quanto no sombreado (café x ingá $\mathrm{x}$ abacateiro). Resultado semelhante foi observado por 
Khouri (2007) em estudos realizados sobre teores de NT entre os terços de cafeeiro mantidos sob gradientes de 0 a $48 \%$ de sombreamento.

Quando as avaliações foram realizadas em março (final da estação chuvosa), no sistema a pleno sol, os teores de NT avaliados às 12 e às $18 \mathrm{~h}$ foram maiores no terço superior dos cafeeiros em comparação ao terço médio (Figura 1). Comportamento contrário foi observado no sistema sombreado, ocorrendo maiores teores de NT no terço médio (Figura 1).

A fase de frutificação e, principalmente, a diferença na disponibilidade hídrica ocorrida entre as duas épocas de avaliação (janeiro e março) foram fatores determinantes para a diferenciação do teor de NT no perfil da planta. Somente quando os índices de pluviosidade foram elevados as diferenças de teores de NT entre os terços superior e médio foram observadas (Figura 1). A água tem grande importância na manutenção da hidratação do protoplasma (Morais et al., 2003) e redistribuição de fotoassimilados e compostos nitrogenados.

Para a avaliação realizada em março, o maior teor de NT verificado no terço superior das plantas mantidas a pleno sol foi relacionado à menor redistribuição e, portanto, maior capacidade de acúmulo de compostos de carbono nesse estrato. Dessa forma, ocorreu um intenso crescimento vegetativo (de ramos, folhas e número de nós). Diferentemente, no terço médio houve redução da capacidade de reserva de NT devido ao auto-sombreamento, fato que restringiu o metabolismo de $\mathrm{N}$. De acordo com Ishida et al. (1999), a relação entre o teor de clorofila e nitrogênio foi menor nas folhas do estrato superior em relação ao inferior em uma espécie arbórea tropical (Dryobalanops aromatica Gaertn.f.). Entretanto, de acordo com Hallik et al. (2009), devido ao ritmo diferenciado de composição foliar da copa, espécies arbóreas decíduas são muito mais susceptíveis ao efeito da exposição à luz em relação às espécies arbustivas.

Para o sistema sombreado nessa mesma avaliação (Figura 1), sugere-se que as maiores médias verificadas no terço médio do cafeeiro tenham ocorrido devido à presença de folhas completamente formadas e aclimatadas em relação ao terço superior. Tal comportamento possibilitou disponibilidade de esqueletos de carbono e poder redutor no metabolismo celular para os frutos, que se constituíram nos drenos principais desse estrato. Devido à restrição de a radiação promover redução do florescimento, ocorreu superávit desses produtos, que resultou em elevação do teor de NT foliar. No terço superior, estrato com alto número de folhas em formação, a restrição de luz proporcionada pela restrição de luz das árvores influenciou negativamente o acúmulo de nitrogênio.

Em janeiro, para os terços médio e terço superior dos cafeeiros maior teor de NT foliar foi observado para o sistema sombreado em comparação ao sistema a pleno sol (Figura 1). Nos sistemas avaliados em janeiro (veranico), a restrição de luz resultou no aumento da assimilação de nitrogênio (Figura 1). O componente arbóreo contribuiu na manutenção da umidade do solo (dados não mostrados) e também no fornecimento de $\mathrm{N}$, visto que nesse sistema houve presença de uma espécie leguminosa. Além

\section{JANEIRO}
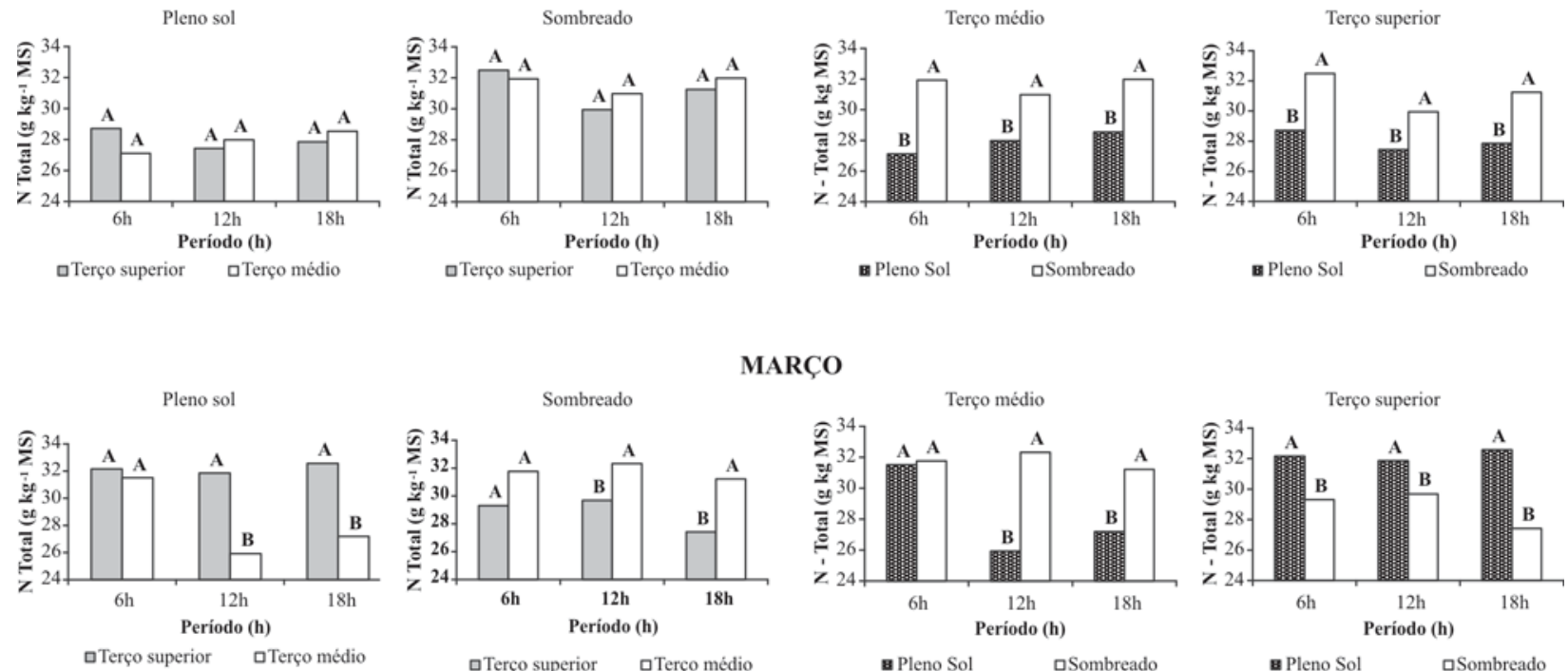

MARÇO

Figura 1. Teores de $\mathrm{N}$ total foliar de cafeeiro (Coffea arabica L.) cv. Catuaí, cultivado em sistema a pleno sol e associado com abacateiro (Persea americana) e ingazeiro (Inga edulis), avaliado nos terços superior e médio, na estação úmida, sob veranico de janeiro e final da estação (março).

*Letras distintas entre duas barras consecutivas representam diferença entre médias (cinco repetições), pelo teste t (p =10\%).

Rev. Ceres, Viçosa, v. 57, n.1, p. 034-041, jan/fev, 2010 
disso, as folhas do cafeeiro cultivado sobre sombra são maiores, com menor massa específica, proporcionando maior eficiência da interceptação da radiação disponível no sistema (Morais et al., 2003). Os teores de NT verificados neste estudo foram semelhantes aos descritos por Andrade Netto (2005).

Quando as avaliações foram realizadas em março (final da estação chuvosa), maiores teores de NT foram observados no sistema a pleno sol apenas para as avaliações do terço superior. Para aquelas do terço médio, maiores teores de NT foram verificadas no sistema sombreado (Figura 1). Em estudo realizado na Etiópia, Bote (2007) verificou maiores teores de $\mathrm{N}$ foliar em cafezais arborizados, em comparação aos mantidos a pleno sol. Entretanto, a partir das observações no presente trabalho, torna-se evidente a variabilidade de comportamento dos sistemas quando diferentes estratos da copa do cafeeiro são analisados. Tal divergência de comportamento em relação aos teores de NT foi relacionada à concentração de carga de frutificação. Para os cafeeiros mantidos a pleno sol, foi verificada maior concentração de carga de frutificação no terço médio da copa dos cafeeiros; para os cafeeiros arborizados, o maior pegamento de frutos foi observado no terço superior. Segundo Vaast et al. (2005), em estudo realizado com cafeeiros de cinco anos de idade, cv. Costa Rica 95, o transporte de fotoassimilados para os frutos foi quatro vezes superior ao observado para os ramos durante o terceiro ciclo de produção da cultura. Em decorrência dessa elevada capacidade de acúmulo de carboidratos Da Matta et al. (2008), verificaram que, na fase final de crescimento, os frutos podem acumular até 95\% do $\mathrm{N}$ absorvido, constituindo-se, desta forma, também em potente dreno desse nutriente. Dwomoh et al. (2008) verificaram relação linear positiva entre doses de $\mathrm{N}$ fornecidas a cafeeiros e níveis de $\mathrm{N}$ dos frutos.

Uma análise geral sobre o comportamento do teor de nitrato $\left(\mathrm{N}-\mathrm{NO}_{3}{ }^{-}\right)$revelou que ocorreram diferenças entre os dois terços do cafeeiro cultivado a pleno sol e sombreado em janeiro às 6 e 12 h, respectivamente (Figura 2).

Em março o teor de $\mathrm{NO}_{3}{ }^{-}$foliar diferiu às $18 \mathrm{~h}$ para $\mathrm{o}$ sistema a pleno sol (Figura 2), enquanto no sistema sombreado foi detectada diferença às 6 e 12 h (Figura 2). Analisando os dois sistemas no mesmo período de avaliação, foram observados teores mais elevados de N$\mathrm{NO}_{3}{ }^{-}$no terço superior do cafeeiro em todo período de coleta, com exceção das 18 h no sistema sombreado, que apresentou comportamento contrário (Figura 2). De modo geral, verificou-se variação nos teores de nitrato nos dois sistemas nas duas épocas avaliadas ao longo de todo ciclo diurno. Resultado divergente foi constatado por Queiroz et al. (1993), em estudos realizados com mudas de cafeeiros Catuaí vermelho, em casa de vegeta- ção, com seis meses de idade. Esses autores observaram aumento gradual no teor de nitrato durante o ciclo fotoperiódico entre 6 e 18 h. No entanto, entre 18 e 24 horas o nitrato foliar decresceu. Essa inversão de comportamento foi relacionada aos diferentes estágios dos dois estudos. Para o referido estudo, as plantas jovens estavam em casa de vegetação, ambiente totalmente controlado, e possuíam particularidades anatômicas das folhas e características metabólicas diferentes de plantas em condição de campo que tinham estruturas vegetativas já estabilizadas, além disso, os cafeeiros apresentavam carga de frutificação.

Em estudos realizados por Amaral et al. (2001) com café arábica, em Viçosa, MG, foi verificado que, embora a presença de frutos nas plantas condicione maior fluxo de nitrato às folhas, o conteúdo de $\mathrm{N}-\mathrm{NO}_{3}{ }^{-}$foliar em cafeeiros, com e sem frutificação, foi semelhante. Tal comportamento foi relacionado à maior atividade da enzima redutase do nitrato nas folhas de plantas com frutos, concomitantemente ao direcionamento de transporte de $\mathrm{N}-\mathrm{NH}_{4}{ }^{+}$das folhas para os frutos. Acredita-se que as maiores médias de nitrato observadas no terço superior dos dois sistemas avaliados em março ocorreram devido à maior disponibilidade hídrica, resultando em maior transpiração ocorrida nas folhas nesse período (Figura 2). Em razão de o nitrato ser transportado preferencialmente através do xilema, acompanhando a corrente transpiratória, tal condição pode ter contribuído para a absorção e transporte de nitrato até esse terço. Segundo Coll et al. (2001), o transporte majoritário do nitrato se dá através do xilema até os órgãos superiores, onde ocorre o processo de redução e assimilação.

De modo geral, verificaram-se diferenças nos teores foliares de $\mathrm{N}_{-} \mathrm{NO}_{3}{ }^{-}$entre os dois sistemas, nos terços médio e superior, em avaliação realizada em janeiro (Figura 2). Conforme se observa na Figura 2, em avaliação realizada em março, foram detectadas diferenças nos teores de $\mathrm{N}-\mathrm{NO}_{3}^{-}$entre os sistemas a pleno sol e sombreado nos dois terços, com exceção das 18 h para o terço médio. Os teores mais elevados de nitrato foram verificados no sistema a pleno sol nas duas avaliações (janeiro e março) em todos os horários de coleta das folhas dos cafeeiros (Figura 2). No presente trabalho, o acúmulo de nitrato nos tecidos foliares nos diferentes sistemas pode estar relacionado à menor atividade da enzima redutase do nitrato. A atividade dessa enzima depende de níveis e fatores de regulação. As atividades gênica e enzimática são os principais níveis de regulação, que são controlados por fatores como: luz, concentração de nitrato, glicose, trioses fosfato e glicose3-fosfato. Portanto, embora a luz e o teor de nitrato sejam importantes fatores de controle da atividade da enzima redutase do nitrato, no presente estudo a 


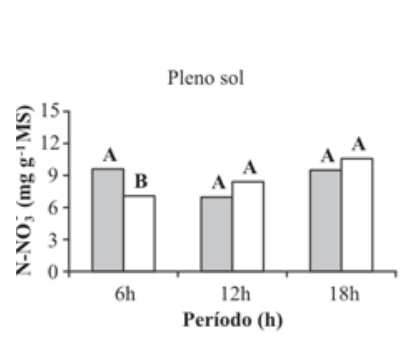

口Terço superior aTerço médio

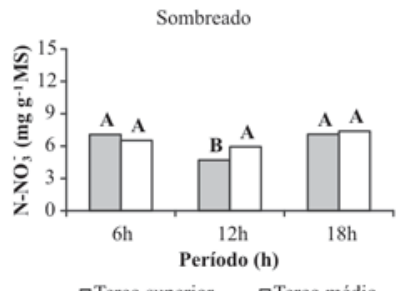

口Terço superior aTerço médio
JANEIRO

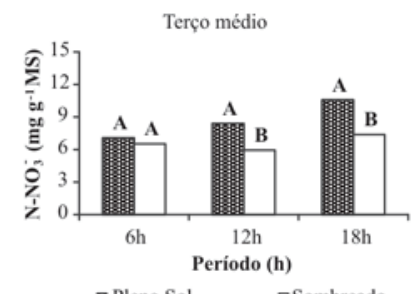

a Pleno Sol aSombreado

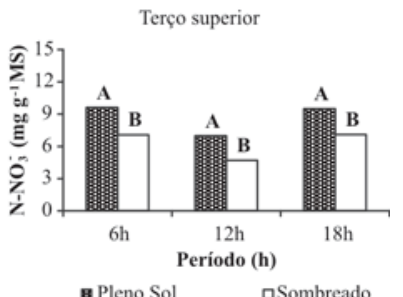

BPleno Sol aSombreado
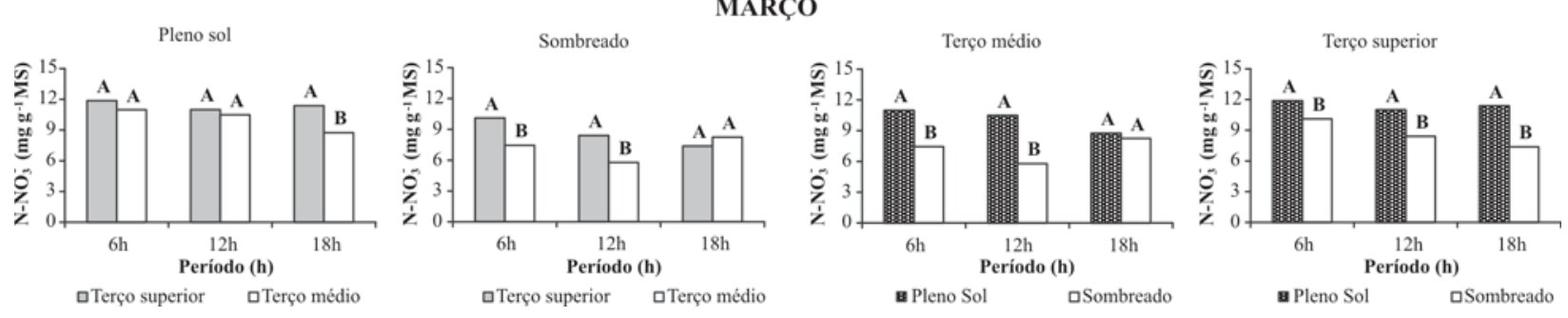

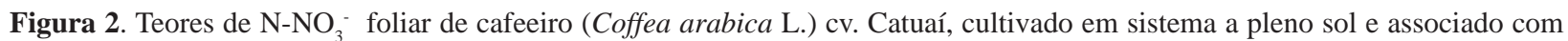
abacateiro (Persea americana) e ingazeiro (Inga edulis), avaliado nos terços superior e médio, na estação úmida, sob veranico de janeiro e final da estação (março).

*Letras distintas entre duas barras consecutivas representam diferença entre médias (cinco repetições), pelo teste $t$ ( $p=10 \%)$.

luz parece ter sido um fator preponderante sobre o teor de nitrato. Para esclarecer tais fatos, estudos sobre a regulação das atividades gênica e enzimática em cafeeiros devem ser realizados.

A análise do teor de N-orgânico (NORG) entre os terços do cafeeiro a pleno sol e em sistema sombreado em avaliação realizada em janeiro não revelou diferença estatística durante todo o ciclo diurno. As médias se igualaram em ambos os sistemas (Figura 3).

Para a avaliação realizada em março (final da estação chuvosa) foram observadas maiores médias de NORG no terço superior do cafeeiro a pleno sol em relação ao sistema sombreado. Entretanto, comportamento contrário foi verificado para o sistema sombreado na mesma época, em que se observaram maiores teores de NORG no terço médio. Essas diferenças verificadas em março seguem comportamento semelhante ao observado quando se avaliou o NT. A diferença na disponibilidade hídrica nas duas épocas foi também um fator preponderante que determinou essa diferenciação nos teores de NORG entre os terços avaliados. O NORG representa a fração de nitrogênio que, após incorporação de carboidratos, pode ser retranslocado para os frutos e folhas adjacentes. No terço superior do sistema a pleno sol e no terço médio do sistema sombreado, devido à menor ocorrência de botões florais, foi observada redução do direcionamento de fotoassimilados e $\mathrm{N}$ para os frutos, consequentemente aumentou a concentração de NORG nas folhas. Em estudo realizado por Khouri (2007) não foram encontra- das diferenças nos teores de NORG foliar no perfil da planta quando avaliado durante o ciclo reprodutivo com níveis de sombreamento variando de 0 a $48 \%$. Para o presente trabalho, as variações observadas de teores de NORG verificadas em março se devem ao fato de o sistema associado apresentar intensa restrição de radiação (96,2\% de sombreamento), também devido ao menor vigor dos cafeeiros resultante das condições de baixo índice pluviométrico anual de 570,8 mm.

Foram detectados teores mais elevados de NORG no sistema sombreado para o terço médio nos dois períodos de avaliação (Figura 3). A concentração da frutificação dos cafeeiros mantidos a pleno sol, no terço médio da planta, condicionou intenso transporte de NORG para os frutos, reduzindo o NORG das folhas. Quando foi avaliado o terço superior, em janeiro os teores de NORG nas folhas de cafeeiros sombreados foram superiores aos das plantas mantidas a pleno sol (Figura 3). Entretanto, nas avaliações realizadas em março os teores de NORG foram semelhantes para os dois sistemas (Figura 3). De acordo com CHeng \& Schupp (2004), o transporte, metabolismo e acúmulo de açúcares nos frutos, de maneira geral, estão condicionados por fatores ambientais e práticas culturais. Os cafezais arborizados caracterizam-se por um período mais longo de permanência de fruto nas plantas (Muschler, 2001), resultando em maior capacidade de acúmulo de metabólitos, principalmente açúcares solúveis (Franck et al., 2006) e compostos nitrogenados (Amaral et al., 2001). Dessa forma, em janeiro, devido ao estágio de 


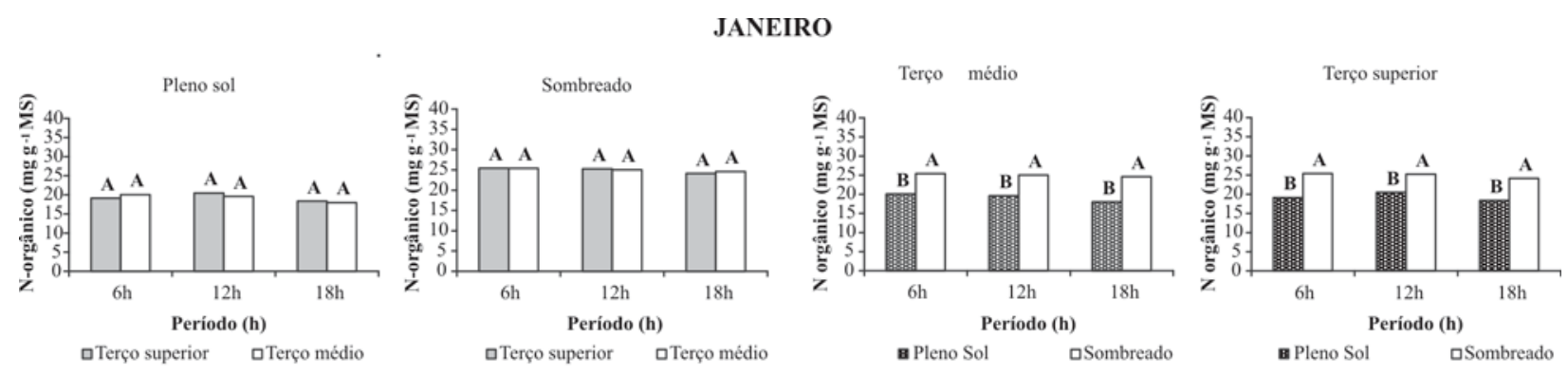

MARÇO
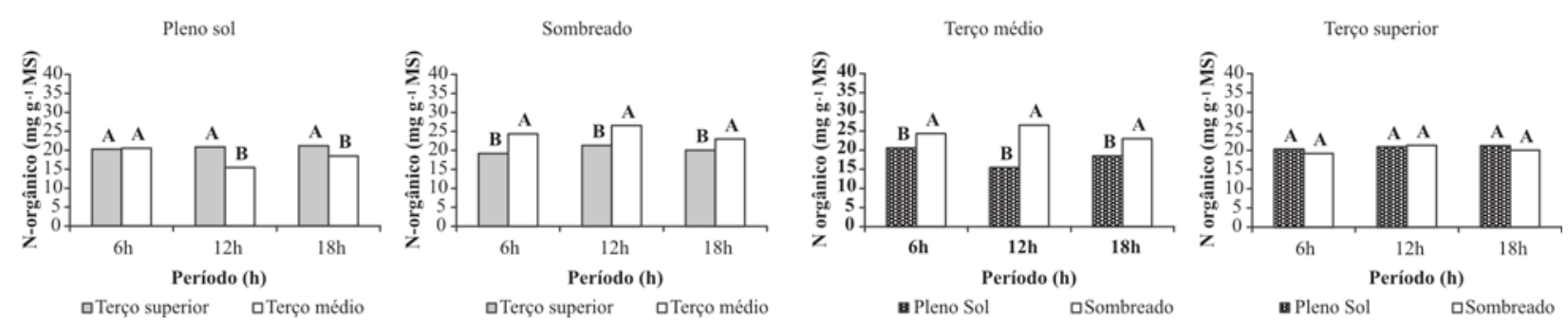

Figura 3. Teores de N- Orgânico foliar de cafeeiro (Coffea arabica L.) cv. Catuaí, cultivado em sistema a pleno sol e associado com abacateiro (Persea americana) e ingazeiro (Inga edulis), avaliado nos terços superior e médio, na estação úmida, sob veranico de janeiro e final da estação (março).

*Letras distintas entre duas barras consecutivas representam diferença entre médias (cinco repetições), pelo teste $t$ (p =10\%).

desenvolvimento inicial dos frutos e à menor carga nos sistemas sombreados, menor capacidade de transporte de NORG para os frutos resultou em acúmulo de NORG nas folhas no terço superior dos cafeeiros sob arborização. A redução dos valores de NORG nas folhas dos cafeeiros sombreados promoveu igualdade de teores em março para os dois sistemas. Nos sistemas arborizados o teor de NORG foi reduzido, devido às maiores taxas de transporte das folhas do terço médio para os frutos que, nessa época, encontravam-se em estágio mais avançado de desenvolvimento.

Para a avaliação realizada em janeiro nos sistemas a pleno sol e sombreado foi observada diferença às $18 \mathrm{~h}$ na atividade da redutase do nitrato (RN) entre os terços (Figura 4). Nesse horário, maior atividade da RN foi detectada no terço superior, para os dois sistemas de cultivo de café (Figura 4).

As maiores médias da atividade enzimática da RN observadas às $18 \mathrm{~h}$ em janeiro, no terço superior, foram relacionadas às possíveis alterações da disponibilidade de carboidratos durante o período luminoso no perfil da planta (Queiroz et al., 1993). Segundo Bachmann et al., (1995), a RN pode ser ativada na ausência de luz mediante o fornecimento de açúcar às folhas.

Quando as avaliações foram realizadas em março, foi observado comportamento contrário ao do mês de janeiro. Para o sistema a pleno sol, as médias da atividade da RN se igualaram entre os terços avaliados (Figura 4). No entanto, para o sistema sombreado foram observadas di- ferenças, ocorrendo maiores médias da atividade da RN no terço médio do cafeeiro (Figura 4). Essa diferença entre os terços foi marcante às 6 e às $18 \mathrm{~h}$ para o sistema sombreado em março (Figura 4).

A diferença no estágio de desenvolvimento do cafeeiro, ocorrida entre as duas avaliações (janeiro e março), foi o fator determinante para a diferenciação da atividade enzimática da RN no perfil da planta. Em estudos realizados por Carelli \& Fahl (2006), foi observado que a atividade da RN nas folhas do cafeeiro aumenta nas fases fenológicas com intensa demanda de metabólitos e nutrientes dos drenos.

De maneira geral, verificaram-se maiores médias da atividade enzimática da RN no cafeeiro cultivado em sistema sombreado nas duas épocas avaliadas, com maior atividade enzimática da RN ao meio-dia (Figura 4). Entretanto, comportamento anômalo em relação à tendência foi observado no terço médio em janeiro, quando comparados os dois sistemas em estudo (Figura 4). Em relação ao terço superior nesse mesmo período de avaliação, notam-se diferenças onde maior atividade enzimática da RN foi observada às 12 e às 18 h no sistema sombreado (Figura 4).

Em março, para os dois terços foram detectadas diferenças nas médias da atividade da RN (Figura 4). Quando avaliado o terço médio do cafeeiro, observou-se diferença às 6 e às 18 h e no terço superior às 6 e às 12 h, com o sistema sombreado apresentando maior atividade enzimática da RN (Figura 4). 


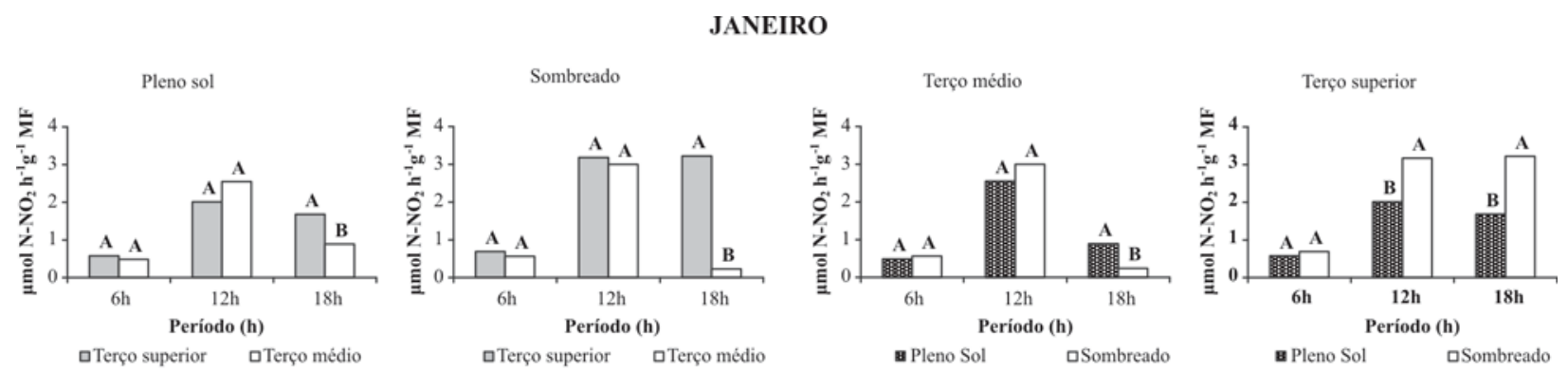

\section{MARÇO}
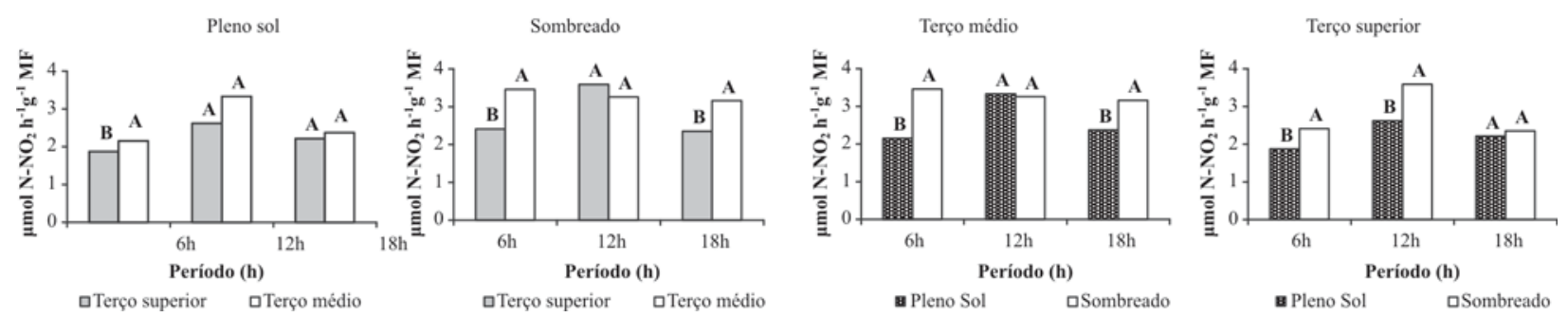

Figura 4. Atividade da redutase do nitrato em folhas de cafeeiro (Coffea arabica L.) cv. Catuaí, cultivado em sistema a pleno sol e associado com abacateiro (Persea americana) e ingazeiro (Inga edulis), avaliado nos terços superior e médio, na estação úmida, sob veranico de janeiro e final da estação (março).

*Letras distintas entre duas barras consecutivas representam diferença entre médias (cinco repetições), pelo teste $t$ (p =10\%).

As maiores médias da atividade enzimática da RN observadas no sistema sombreado foram favorecidas pela restrição da radiação luminosa promovida pela presença das árvores, que condicionou um microclima favorável à atividade da enzima (Figura 4). Em estudos realizados por Andrade Netto (2005) em cafeeiro arábica, observou-se uma atividade superior da RN durante o período luminoso na ocasião de maior irradiância. Segundo o autor, o aumento da atividade da $\mathrm{RN}$ às $12 \mathrm{~h}$ a meia sombra $(50 \%$ de luz) foi consequência da absorção de nitrogênio do solo, uma vez que a condutância estomática e a taxa de transpiração mantiveram o fluxo xilemático, tendo apresentado valores superiores àqueles obtidos nas plantas a pleno sol.

\section{CONCLUSÃO}

No período de veranico (janeiro), os cafeeiros arborizados apresentam maiores teores de $\mathrm{N}$ total, resultante do maior acúmulo de $\mathrm{N}$ orgânico. A maior atividade enzimática da redutase do nitrato nas plantas sombreadas tem contribuição marcante para tal efeito.

\section{AGRADECIMENTOS}

Ao Programa Nacional de Pesquisa e Desenvolvimento do Café (PNP\&D/Café) - Embrapa/Café, pela concessão de bolsa; e ao Programa de Pós-graduação em Agronomia da UESB, pela oportunidade da obtenção do título de Mestre.

\section{REFERÊNCIAS}

Amaral JAT, Da Matta FM \& Rena AB (2001) Effects of fruiting on the growth of arabica coffee trees as related to carbohydrate and nitrogen status and to nitrate reductase activity. Brazilian Journal of Plant Physiology, 13:66-74.

Andrade Netto JF de (2005) Atividade das enzimas redutase do nitrato e glutamina sintetase em cafeeiro arábica. Dissertação de Mestrado. Escola Superior de Agricultura Luiz de Queiroz, Piracicaba, 60p.

Bachmann M, McMichael RW Jr., Huber JL, Kaiser WM \& Huber SC (1995) Partial purification and characterization of a calciumdependent protein kinase and an inhibitor protein required for inactivation of spinach leaf nitrate reductase. Plant Physiology, 108:1083-1091.

Bote AD (2007) Physiological effect of shade on growth and production of organic coffee in Ethiopia. Masters Thesis. Wageningen University, Wageningen, 74p.

Carelli MLC \& Fahl JI (2006) Partitioning of nitrate reductase activity in Coffea arabica L. and its relation to carbon assimilation under different irradiance regimes. Brazilian Journal of Plant Physiology, 18:397-406.

Cataldo DA, Harron M, Schrader LE \& Youngs VL (1975) Rapid colorimetric determination of nitrate in plant tissue by nitrification of salicylic acid. Communication Soil Science and Plant Analysis, 6:71-81.

Cheng L \& Schupp, J (2004) Nitrogen fertilization of apple orchards (2004) New York fruit quarterly, 12:22-25.

Coll JB, Rodrigo GN, García BS \&Tamés RS (2001) Fisiologia vegetal. 9a . ed. Editora Piramide, Madrid, 568p.

Da Matta FM, Ronchi CP, Maestri M \& Barros RS (2008) Ecophysiology of coffee growth and production. Brazilian Journal Plant Physiology, 19:485-510. 
Dwomoh EA, Ofori-Frimpong K, Afrifa AA \& Appiah MR (2008) Effects of fertilizer on nitrogen contents of berries of three coffee clones and berry infestation by the coffee berry borer, Hypothenemus hampei (Ferrari) (Coleoptera: Scolytidae). African Journal of Agricultural Research, 3:111-114.

Franck N, Vaast P, Génard M \& Dauzat J (2006) Soluble sugars mediate sink feedback down-regulation of leaf phtosynthesis in field-grown Coffea arabica. Tree Physiology, 26:517-525.

Hallik L, Niinemets U \& Wright IJ (2009) Are species shade and drought tolerance reflected in leaf-level structural and functional differentiation in Northern Hemisphere temperate woody flora? New Phytologist, 184:257-274.

Ishida A, Uemura A, Koike N, Matsumoto Y \& Hoe AL (1999) Interactive effects of leaf age and self-shading on leaf structure, photosynthetic capacity and chlorophyll fluorescence in the rain forest tree Dryobalanops aromatica. Tree Physiology, 19:741-747.

Khouri ICR (2007) Atividade da redutase do nitrato, teores de nitrogênio e de carboidratos em cafeeiro influenciados pelo sombreamento e estádio fenológico. Dissertação de Mestrado. Universidade Federal de Viçosa, Viçosa, 63p.

Lima Filho OF de \& Malavolta E (2003) Studies on mineral nutrition of the coffee plant (Coffea arabica L. cv. Catuaí Vermelho): LXIV. Remobilization and re-utilization of nitrogen and potassium by normal and deficient plants. Brazilian Journal of Biology, 63:481-490.

Matsumoto SN, Faria GO, Viana AES, Rocha VS \& Novaes AB (2006) Water relations in a coffee grove planted with grevilleas in Vitória da Conquista, Bahia, Brazil. Coffee Science, 1:71-83.
Morais H, Marur CJ, Caramori PH, Ribeiro, AM de A \& Gomes JC (2003) Características fisiológicas e de crescimento de cafeeiro sombreado com guandu e cultivado a pleno sol. Pesquisa Agropecuária Brasileira, 38:1131-1137.

Muschler RG (2001) Shade improves coffee quality in a sub-optimal coffee-zone of Costa Rica. Agroforestry Systems, 85:131-139.

Queiroz CGS, Alves JD \& Rena AB (1991) Efeito do cloranfenicol, propanol, $\mathrm{pH}$ e temperatura sobre a atividade in vivo da redutase de nitrato em cafeeiros jovens. Revista Brasileira de Botânica, 14:73-77.

Queiroz CGS, Rena AB, Cordeiro AT \& Alves JD (1993) Ritmo diurno na atividade da redutase de nitrato em folhas e raízes de Coffea arabica L. Pesquisa Agropecuária Brasileira, 28:787-795.

Ribaski J, Montoya LJ \& Rodigheri HR (2002) Sistemas Agroflorestais: aspectos ambientais e sócio-econômicos. Disponível em: <www.planetaorganico.com.br/TrabRibaski.htm> Acessado: em 10 de maio de 2008.

SAEG (2000) Sistema para Análises Estatísticas e Genéticas. Fundação Arthur Bernardes. Universidade Federal de Viçosa. Viçosa, MG. Versão 9.1.

Silva DJ \& Queiroz CA (2002) Análise de alimentos: métodos químicos e biológicos. $3^{\mathrm{a}}$ ed. Viçosa, Editora UFV. 235p.

Sousa AS, Silveira, PA, Silva RC, Lima EM \& Maia MRL (2007) Caracterização e classificação climática de Barra do Choça - BA. In: $9^{a}$ Semana de Pesquisa e Pós-Graduação da Uesc, Ilhéus. Anais, UESC. Disponível em <http://www.seminarioicuesc.com.br/sistema/resumos/2007268.pdf.> Acessado em: 18 de junho de 2008.

Vaast P, Angrand J, Franck N, Dauzat J \& Génard M (2005) Fruit load and branch ring-barking affect carbon allocation and photosynthesis of leaf and fruit of Coffea arabica in the field .Tree Physiology, 25:753-760. 